\title{
Association of high-sensitivity C-reactive protein with cardiometabolic risk factors and micronutrient deficiencies in adults of Ouagadougou, Burkina Faso
}

\author{
Augustin N. Zeba ${ }^{1,2_{*}}$, Hélène F. Delisle ${ }^{1}$, Clémentine Rossier ${ }^{3}$ and Genevieve Renier ${ }^{4}$ \\ ${ }^{1}$ Département de Nutrition, Faculté de Médecine, Université de Montréal, C.P. 6128 succ. Centre-ville, Montréal, QC, Canada \\ H3C $3 J 7$ \\ ${ }^{2}$ Institut de Recherche en Sciences de la Santé/Direction Régionale de l'Ouest (IRSS/DRO), O1 BP 545 Bobo Dioulasso O1, \\ Burkina Faso \\ ${ }^{3}$ Institut Supérieur des Sciences de la Population (ISSP), Université de Ouagadougou, O3 BP 7118 Ouagadougou 03, \\ Burkina Faso \\ ${ }^{4}$ Centre Hospitalier Universitaire de Montréal, Département de Médecine, Université de Montréal, 1560 Sherbrooke East, \\ Montréal, QC, Canada H2L $4 M 1$
}

(Submitted 3 February 2012 - Final revision received 14 June 2012 - Accepted 19 June 2012 - First published online 23 August 2012)

\begin{abstract}
Increasing evidence suggests that high-sensitivity C-reactive protein (hs-CRP) is associated with cardiometabolic risk factors (CMRF) while being also related to micronutrient deficiencies. As part of a project on the double burden of under- and overnutrition in sub-Saharan Africa, we assessed the relationship between hs-CRP and both CMRF and micronutrient deficiencies in a population-based cross-sectional study carried out in the Northern district of Ouagadougou, the capital city of Burkina Faso. We randomly selected 330 households stratified by income tertile. In each income stratum, 110 individuals aged 25-60 years and having lived in Ouagadougou for at least 6 months were randomly selected, and underwent anthropometric measurements and blood sample collection. The prevalence of high hs-CRP was $39 \cdot 4 \%$, with no sex difference. Vitamin A-deficient subjects (12.7\%) exhibited significant risk of elevated hs-CRP (OR 2.5; $P=0 \cdot 015)$. Serum ferritin was positively correlated with log hs-CRP $(r 0 \cdot 194 ; P=0 \cdot 002)$. The risk of elevated hs-CRP was significant in subjects with BMI $\geq 25 \mathrm{~kg} / \mathrm{m}^{2}$ (OR 6.9; $95 \%$ CI 3.6, 13.3), abdominal obesity (OR 4.6; $95 \%$ CI $2 \cdot 2,7 \cdot 3)$ and high body fat (OR 10.2; 95\% CI 5.1, 20.3) $(P<0 \cdot 001$, respectively). Independent predictors of hs-CRP in linear regression models were waist circumference $(\beta=0 \cdot 306 ; P=0 \cdot 018)$ and serum TAG $(\beta=0 \cdot 158 ; P=0 \cdot 027)$. In this sub-Saharan population, hs-CRP was consistently associated with adiposity. Assuming that plasma hs-CRP reflects future risk of cardiovascular events, intervention which reduces CRP, or chronic and acute nutrition conditions associated with it, could be effective in preventing their occurrence particularly in sub-Saharan Africa.
\end{abstract}

Key words: Micronutrient deficiencies: Cardiometabolic risk factors: Inflammation: Adults: Burkina Faso

Inflammation is thought to play a key role in the pathophysiology of $\mathrm{CVD}^{(1)}$ as well as in insulin resistance and diabetes mellitus ${ }^{(2)}$. Of the numerous circulating biomarkers of low-grade inflammation thus far studied, C-reactive protein (CRP), when measured in blood with a high-sensitivity assay, seems to have the most consistent relationship with the risk of cardiometabolic diseases in a variety of clinical settings ${ }^{(3,4)}$. The Physicians Health Study in 1997 reported that CRP is a strong and independent predictor of future cardiovascular events among apparently healthy asymptomatic men ${ }^{(3)}$. Since this report, the ability of CRP to predict cardiovascular events has been confirmed in many other studies $^{(5-7)}$, providing evidence of the pathogenic role of inflammation in atherosclerosis ${ }^{(8)}$. A recent meta-analysis of fifty-four long-term prospective studies suggested a continuous association of high-sensitivity CRP (hs-CRP) with the risk of CHD, IHD and vascular mortality independently of conventional risk factors ${ }^{(9)}$. However, the independent predictive value of hs-CRP has been questioned in some studies $^{(5,10)}$ and it seems that a closer relationship exists between hs-CRP and traditional cardiometabolic risk rather than first anticipated ${ }^{(11,12)}$.

Abbreviations: CMRF, cardiometabolic risk factor; CRP, C-reactive protein; HDL-C, HDL-cholesterol; HOMA, homeostasis model assessment; hs-CRP, highsensitivity C-reactive protein; LDL-C, LDL-cholesterol; TC, total cholesterol; WC, waist circumference.

*Corresponding author: Dr A. N. Zeba, fax +1 51434373 95, email nawidzeb@yahoo.fr 
Studies in African populations have usually focused on the relationship between inflammation and infectious diseases $^{(13,14)}$ or micronutrient deficiencies ${ }^{(15-17)}$, probably because until recently these conditions were the main health concerns for these populations. However, studies on the association between hs-CRP and cardiometabolic risk factors (CMRF) and diseases may be more relevant, as the subSaharan Africa population, while still in the midst of nutrition deficiencies, is experiencing an epidemic of cardiometabolic disease with the associated high rate of mortality ${ }^{(18-22)}$. We have indeed, in the adult population of Ouagadougou, previously reported a high prevalence rate of overweight/ obesity, abdominal obesity, hypertension, hyperglycaemia and low HDL-cholesterol (HDL-C) (24.2, 12.5, 21.9, 22.3 and $30 \%$, respectively), along with a high prevalence of vitamin A deficiency, Fe deficiency and anaemia (12.7, 15.4 and $25.5 \%$ of subjects, respectively). In $23.5 \%$ of them, we observed the co-occurrence of at least one CMRF plus at least one micronutrient deficiency ${ }^{(23)}$. In an attempt to halt the progression of cardiometabolic diseases, effective prevention should start with unravelling the network of multiple risk factors. The present cross-sectional study carried out in Ouagadougou was designed to assess CMRF and nutritional deficiencies in adults. It also aimed at understanding whether inflammation is correlated with these CMRF, and to what extent this relationship is modulated by micronutrient deficiencies. One of the hypotheses was that hs-CRP is associated with both traditional CMRF and micronutrient deficiencies. The present study describes the relationship of CMRF with hs-CRP in adults of Ouagadougou, while taking into account their micronutrient status.

\section{Methods}

\section{Population and sample}

The study was carried out in 2010 in the northern part of Ouagadougou where a population observatory has been in operation since 2008, with periodic collection of socioeconomic, demographic and health data in a population sample of 80000 individuals. This part of the capital city is a vulnerable area on socio-economic and health grounds according to data from national and international institutions $^{(24)}$. The study sample of 330 subjects aged 25-60 years and stratified by income was selected using the observatory database. The availability of data on this part of Ouagadougou such as household identification, socio-economic and demographic data led to the selection of the present study location. The database included 13021 households with at least one individual aged between 25 and 60 years. A proxy of household income was derived using principal components analysis, with twelve discriminatory household asset variables (ownership of house telephone, television, DVD player, fridge, motorbike, car; type of household toilet; electricity; type of cooking fuel; and type of floor, roof and walls). Households were split into tertiles of this income proxy. For each tertile, 110 households were randomly selected, with fifty additional households as alternates. Only one subject per household was enrolled. The field team consisted of a clinician (first author, A. N. Z.), and an experienced laboratory technician and two research assistants trained by A. N. Z.

Eligible participants were Burkinabe-born adults aged 25-60 years who had been living in Ouagadougou for at least 6 months and did not expect to move until the end of the study. Subjects with a prior diagnosis of hypertension or diabetes were not excluded from the study. Pregnant or lactating women, as well as physically and mentally disabled subjects, were excluded.

A sample size of 300 subjects aged 25-60 years was deemed adequate to determine the prevalence of the double burden of overweight/obesity and micronutrient malnutrition in the same individuals, which was estimated to be $10 \%$ by taking into account the overweight/obesity prevalence of $33 \%(25)$, and limited access to micronutrient-rich food in $65.6 \%$ of households in Ouagadougou ${ }^{(26)}$. The precision was $\pm 3 \%$, with a statistical power of $80 \%$ and a CI of $95 \%$, and with an $\alpha$ error of $<0.05$ using the PASS software (Power Analysis and Sample Size; supplied by NCSS). The size of the sample was increased by $10 \%$ up to 330 , to provide for dropouts, missing subjects and incomplete datasets.

\section{Study variables}

After enrolment, personal interviews with participants provided information on age, parity, education level, psychosocial factors and lifestyle patterns. Anthropometric and clinical data as well as blood samples were also collected. Psychosocial and lifestyle data are not presented for the present study.

\section{Anthropometrics and body composition}

Body weight was measured to the nearest $100 \mathrm{~g}$ with subjects in light clothing and without shoes, using a portable electronic scale of $150 \mathrm{~kg}$ capacity (Seca 803 Clara Scale). Height was measured to the nearest $0.5 \mathrm{~cm}$ using a portable locally built stadiometer, with the subject standing upright on a flat surface without shoes, and the back of the heels and the occiput against the stadiometer. Waist circumference (WC) was measured to the nearest $0 \cdot 1 \mathrm{~cm}$ with a flexible non-stretch and tension-regulated steel tape (Gulick measuring tape $\left(C_{\text {; }}\right.$ Creative Health Products, Inc.) at the midpoint between the lowest rib and the iliac crest while subjects were standing and breathing normally ${ }^{(27)}$. The average of two separate measures of body weight, height and WC was used in the analyses. BMI was calculated as weight (kg) divided by height $\left(\mathrm{m}^{2}\right)$. BMI was categorised as follows: underweight, $<18.5 \mathrm{~kg} / \mathrm{m}^{2}$; normal, $18.5-24.9 \mathrm{~kg} / \mathrm{m}^{2}$; overweight, $25-29 \cdot 9 \mathrm{~kg} / \mathrm{m}^{2}$; obese, $\geq 30 \mathrm{~kg} / \mathrm{m}^{2(28)}$. Abdominal obesity was defined as WC $\geq 94 \mathrm{~cm}$ for men and $\geq 80 \mathrm{~cm}$ for women ${ }^{(29)}$. Bioelectrical impedance analysis (BIA) was performed to measure body composition (RJL System; Quantum II). For BIA measurements, subjects had to be in the fasting state for at least $12 \mathrm{~h}$, had not to have engaged in vigorous work or physical activity during the last $24 \mathrm{~h}$ and had to have abstained from alcohol for $48 \mathrm{~h}$. The individual was lying on a non-conductive surface with a minimum of 
clothing before placing the electrodes on the hand and foot of the same body side (left or right). We computed percentage body fat using the prediction equation for fat-free mass suggested by Sun et al. for several race/ethnicity groups ${ }^{(30)}$. High body fat was defined as percentage body fat $>25 \%$ in men, and $>33 \%$ in women, as suggested for both black and white subjects ${ }^{(31)}$.

\section{Blood pressure}

Blood pressure was measured by the first author (A. N. Z.) with a calibrated aneroid sphygmomanometer on the right arm of seated subjects after a minimum of 10 min rest. Systolic and diastolic blood pressure was measured twice with an interval of $10 \mathrm{~min}$ between the first and the second measurement. The mean of the two readings was used in the analyses. High blood pressure for subjects without prior diagnosis of hypertension was defined as systolic blood pressure $\geq 130 \mathrm{mmHg}$ or diastolic blood pressure $\geq 85 \mathrm{mmHg}^{(29)}$.

\section{Blood sampling and laboratory measures}

Venous blood samples were drawn after an overnight fast of at least $12 \mathrm{~h}$, in $10 \mathrm{ml}$ EDTA and dry tubes for plasma and serum collection, respectively. Blood samples were immediately stored in cold boxes and brought to the laboratory within $2 \mathrm{~h}$. Samples were centrifuged at $3000 \mathrm{rpm}$ for $10 \mathrm{~min}$, sampled in cryotubes and frozen at $-32^{\circ} \mathrm{C}$. Fasting glucose was immediately determined from plasma samples using the glucose oxidase method at the medical analysis laboratory of the University of Ouagadougou. Hyperglycaemia was defined as fasting plasma glucose $>5.6 \mathrm{mmol} / \mathrm{l}$ for subjects without prior diagnosis of diabetes ${ }^{(29)}$. Plasma hs-CRP was determined by immunonephelometry ( $\mathrm{N}$ Latex CRP mono; Behringwerke AG) using a nephelometer BNA Behring, with a detection threshold of $0.17 \mathrm{mg} / \mathrm{l}$ and a $\mathrm{CV}$ of less than $5 \%$. On the basis of data obtained from the Centers of Diseases Control/ American Heart Association, hs-CRP levels associated with low, moderate and high cardiovascular risk were: $<1 \mathrm{mg} / \mathrm{l}$; $1-3 \mathrm{mg} / \mathrm{l}$; and $>3 \mathrm{mg} / \mathrm{l}$ and $\leq 10 \mathrm{mg} / 1$, respectively ${ }^{(32,33)}$. Plasma concentrations of HDL-C, LDL-cholesterol (LDL-C) and TAG were determined by enzymic methods. Cut-offs for low HDL-C were $<1.0 \mathrm{mmol} / 1$ for men and $<1.3 \mathrm{mmol} / \mathrm{l}$ for women. The cut-off for high plasma LDL-C was $>3.37 \mathrm{mmol} / \mathrm{l}$. Hypertriacylglycerolaemia was defined as plasma TAG concentration $>1.7 \mathrm{mmol} / \mathrm{l}^{(29,34)}$. The total cholesterol (TC):HDL-C ratio was computed and a value $>5$ for men and $>4$ for women was defined as high ${ }^{(35)}$. Serum insulin concentration was measured by radioimmunoassay (Cisbio Bioassays) and the homeostasis model assessment $($ HOMA) equation $(($ fasting glycaemia $\times$ serum insulin) $/ 22.5)$ was used as an index of insulin resistance. Insulin resistance (HOMA-IR) was defined as HOMA $\geq 75$ th centile in the whole study population ${ }^{(36)}$. Serum retinol was measured using HPLC at the University of Ouagadougou, with a serum retinol level $<0.7 \mu \mathrm{mol} / \mathrm{l}$ being indicative of vitamin $\mathrm{A}$ deficiency $^{(37)}$. Plasma ferritin level was measured using chemiluminescence with a cut-off of $<15 \mu \mathrm{g} / \mathrm{l}$ for Fe depletion, and
$\mathrm{Hb}$ was directly measured in the field with a drop of whole blood using HemoCue ${ }^{\circledR}$ (Hemocue HB 201+), with anaemia being defined as $\mathrm{Hb}<130 \mathrm{~g} / 1$ in men and $<120 \mathrm{~g} / 1$ in women ${ }^{(38)}$. Insulin, hs-CRP, ferritin and blood lipid determination were carried out at the Laboratoire de pathologie cellulaire et moléculaire en nutrition, Faculté de Médicine, Université de Nancy, France.

\section{Metabolic syndrome}

According to the most recently harmonised definition ${ }^{(29)}$, the metabolic syndrome was defined as the clustering within a subject of at least three of the following CMRF: abdominal obesity, hyperglycaemia or treated diabetes, hypertriacylglycerolaemia, low HDL-C, and high blood pressure or treated hypertension.

\section{Statistical analyses}

Data were analysed using IBM-SPSS (version 18.0; SPSS, Inc.). Because the distribution of hs-CRP values was highly skewed, this variable was natural log-transformed for correlation analysis. Results are expressed as geometric mean values with their standard errors or mean values and standard deviations, or percentages with $95 \%$ CI for categorical variables. The Wilcoxon or Kruskal-Wallis rank-sum tests which are not affected by disproportionate numbers of subjects were computed whenever appropriate to assess any difference in the distribution of hs-CRP values between groups of subjects. The $\chi^{2}$ test was used to compare proportions. Logistic regression analysis was performed to calculate the likelihood (OR) of elevated hs-CRP (hs-CRP $>1 \mathrm{mg} / \mathrm{l}$ ) and their $95 \%$ CI. Partial correlation after controlling for income level, sex, age, and education level and micronutrient deficiency markers was used to test the association between log (hs-CRP) and CMRF as continuous variables. Controlled multiple linear regression models of log (hs-CRP) on CMRF and micronutrient deficiency markers were constructed. The level of statistical significance was $P<0.05$.

\section{Ethical considerations}

The present study was conducted according to the guidelines laid down in the Declaration of Helsinki and all procedures involving human subjects were approved by the Ethics Committee of the Faculty of Medicine, University of Montreal, and the Ethics Committee for Health Research of Burkina Faso. The study objectives were clearly explained to participants, selected household heads, and local authorities. A written informed consent was obtained from each study subject before enrolment. Participants were given back their results on blood pressure and glycaemia, and those with abnormal values were referred for diagnosis and treatment, with support by the research project.

\section{Results}

A total of 310 subjects completed the study, giving a response rate of $94 \%$. Out of these, 295 subjects had enough blood for 
hs-CRP measurement and eighteen subjects with hs-CRP concentration $>10 \mathrm{mg} / \mathrm{l}$ were excluded from the analyses as they probably had an infectious or inflammatory disorder ${ }^{(32,33)}$. A total of 277 subjects were included in the final analysis. Table 1 shows the characteristics of the study population, which included $53.4 \%$ of women. Mean age was 36.4 (SD 8.9) years, with no sex difference. Subjects with an elementary school level of education were significantly less numerous than those with no formal education, or higher education level $(P=0 \cdot 025)$. More educated subjects were significantly younger than less educated ones $(P=0.002)$. There was no difference in the number of subjects across income strata $(P=0 \cdot 380)$. Mean hs-CRP did not vary significantly by sex or education level, but subjects in the high-income group exhibited the highest geometric mean concentration of hs-CRP $(P=0 \cdot 006)$. The prevalence of elevated hs-CRP $(>1 \mathrm{mg} / \mathrm{l})$ was $39 \cdot 4 \%$ and did not differ between women and men. More educated subjects, and high-income group subjects as well, exhibited a higher prevalence of elevated hs-CRP ( $40.0 \%, P=0.021$; and $44.1 \%, P<0 \cdot 001$, respectively).

The association of hs-CRP concentration $(\mathrm{mg} / \mathrm{l})$ with CMRF is shown in Table 2 . Subjects with BMI $\geq 25 \mathrm{~kg} / \mathrm{m}^{2}$, abdominal obesity and high body fat had significantly higher hs-CRP concentrations $(P<0.001)$. This was observed in both women and men. High blood pressure or hyperglycaemic subjects did not exhibit higher hs-CRP concentrations compared with normal subjects $(P=0.558 ; \quad P=0.402, \quad$ respectively). Significantly higher hs-CRP concentrations were observed in subjects with high LDL-C, both in women $(1.3 v .0 \cdot 7 ; P=0.016)$ and men (1.6 v. $0.7 ; P=0.046)$. hs-CRP concentration was also high in subjects with a high TC:HDL-C ratio $(1.5 v .0 \cdot 7 ; P=0.001)$. In men only, low levels of HDL-C were associated with higher hs-CRP concentrations ( $1 \cdot 0 v \cdot 0 \cdot 6 ; P=0 \cdot 024)$. Compared with subjects without CMRF, higher hs-CRP concentrations were also noted in women with hypertriacylglycerolaemia (2.9 v. $0.7 ; P=0.049)$, in men with insulin resistance $(0.8$ v. $0.5 ; P=0.059)$ and in subjects with the metabolic syndrome or at least two components (Table 2). hs-CRP concentration (Table 2 ) tended to be higher in vitamin A-deficient subjects $(1.0 v \cdot 0 \cdot 7 ; P=0.064)$, with a significant difference in women $(1 \cdot 2 v \cdot 0 \cdot 7 ; P=0 \cdot 022)$. Similarly, hs-CRP concentration tended to be higher in anaemic subjects compared with nonanaemic subjects $(0 \cdot 8 v \cdot 0 \cdot 7 ; P=0 \cdot 266)$, particularly in men ( 0.9 v. $0.7 ; P=0.094)$. Women with higher serum ferritin concentration, compared with those with normal serum ferritin, exhibited higher hs-CRP concentration (0.0.9 v. $0.5 ; P=0.008)$.

The odds of elevated hs-CRP $(>1 \mathrm{mg} / \mathrm{l})$ was significantly higher in subjects with $\mathrm{BMI} \geq 25 \mathrm{~kg} / \mathrm{m}^{2}$ (OR 6.9; $P<0.001$ ), abdominal obesity (OR 4.6; $P<0.001$ ) and high body fat (OR 10.2; $P<0.001$ ) (Table 3 ). The odds of elevated hs-CRP $(>1 \mathrm{mg} / \mathrm{l})$ was also significantly higher in subjects with high LDL-C (OR $3.4 ; P=0.004)$, in subjects with a high TC:HDL-C ratio (OR $3.3 ; P=0 \cdot 010)$, in subjects with low HDL-C (OR 1.6; $P=0 \cdot 040)$, but not statistically significant in subjects with hypertriacylglycerolaemia (OR $7 \cdot 7 ; P=0.070)$. However, no significant odds of elevated hs-CRP $(>1 \mathrm{mg} / \mathrm{l})$ was observed with insulin resistance. Subjects with the metabolic syndrome exhibited a significant odds of elevated hs-CRP $(>1 \mathrm{mg} / \mathrm{l})(\mathrm{OR}$ 2.4; $P=0.045)$. The OR of elevated hs-CRP ( $>1 \mathrm{mg} / \mathrm{l})$ (Table 3$)$ was $2.5(P=0.015)$ and $1.6(P=0.079)$ in vitamin A-deficient subjects and anaemic subjects, respectively.

Partial correlation analyses, controlling for income, sex, age, education level, $\mathrm{Hb}$, ferritin and serum retinol, demonstrated positive and significant correlations of $\log$ (hs-CRP) with BMI $(r 0.340 ; P<0.0010)$, WC $(r 0.366 ; P<0.001)$, body fat $(r 0.185 ; P=0.003)$, TC:HDL-C ratio $(r 0.152 ; P=0.014)$ and TAG $(r 0.274 ; P<0.001)$ (Table 4$)$. A negative and borderline correlation of $\log$ (hs-CRP) with HDL-C was also noted ( $r-0 \cdot 113 ; P=0.069)$. We tested two regression models of hs-CRP, the first using CMRF alone and the second controlling for $\mathrm{Hb}$, serum ferritin and serum retinol. In the first model, abdominal fat $(\beta=0.307 ; P=0.015)$ and TAG $(\beta=0 \cdot 156$; $P=0.028)$, and in the second model, abdominal fat $(\beta=0.306 ; P=0.018)$ and TAG $(\beta=0.158 ; P=0 \cdot 027)$ were

Table 1. Characteristics of the study population

(Percentages and $95 \%$ confidence intervals, mean values and standard deviations or geometric mean values with their standard errors)

\begin{tabular}{|c|c|c|c|c|c|c|c|c|c|c|c|}
\hline & \multicolumn{2}{|c|}{ Overall } & \multicolumn{3}{|c|}{ Age (years) } & \multicolumn{3}{|c|}{ hs-CRP (mg/l) } & \multicolumn{3}{|c|}{$\% \mathrm{hs}-\mathrm{CRP}>1 \mathrm{mg} / \mathrm{l}$} \\
\hline & $\%$ & $95 \% \mathrm{Cl}$ & Mean & SD & $P^{\star}$ & Geometric mean & SE & $P \dagger$ & $\%$ & $95 \% \mathrm{Cl}$ & $P \ddagger$ \\
\hline Sample (n 277) & & & $36 \cdot 2$ & 8.9 & & 0.7 & 0.1 & & $39 \cdot 4$ & $33 \cdot 7,45 \cdot 1$ & \\
\hline Women $(n$ 148) & 53.4 & $47 \cdot 6,59 \cdot 2$ & 35.5 & 8.7 & & 0.8 & 0.1 & & 39.9 & $32 \cdot 0,47 \cdot 8$ & \\
\hline Men $(n$ 129) & $46 \cdot 6$ & $40 \cdot 8,52 \cdot 4$ & $36 \cdot 9$ & 9.0 & $0 \cdot 167$ & 0.7 & 0.2 & 0.456 & $38 \cdot 8$ & $30 \cdot 4,47 \cdot 2$ & 0.851 \\
\hline \multicolumn{12}{|l|}{ Formal education } \\
\hline None $(n 115)$ & 41.5 & $32 \cdot 5,50 \cdot 5$ & $37 \cdot 7^{\mathrm{a}}$ & 9.0 & & 0.7 & 0.2 & & $34 \cdot 8^{\mathrm{a}}$ & $26 \cdot 1,43 \cdot 5$ & \\
\hline Elementary school ( $n 57)$ & $20 \cdot 6$ & $10 \cdot 1,31 \cdot 5$ & $37 \cdot 3^{a, b}$ & $9 \cdot 3$ & & 0.7 & 0.1 & & $29 \cdot 8^{a, b}$ & $18 \cdot 0,41 \cdot 6$ & \\
\hline $\begin{array}{l}\text { High school and above } \\
(n 105)\end{array}$ & $37 \cdot 9$ & $28 \cdot 6,47 \cdot 2$ & $33 \cdot 8^{\mathrm{c}}$ & $7 \cdot 7$ & 0.002 & $0 \cdot 8$ & 0.2 & $0 \cdot 219$ & $49 \cdot 5^{c}$ & $40 \cdot 0,59 \cdot 0$ & 0.021 \\
\hline \multicolumn{12}{|l|}{ Income level } \\
\hline Low $(n$ 106) & $38 \cdot 3$ & $32 \cdot 5,44 \cdot 1$ & $36 \cdot 3$ & 8.3 & & $0.7^{\mathrm{a}}$ & 0.2 & & $37 \cdot 7^{\mathrm{a}}$ & $28 \cdot 5,46 \cdot 9$ & \\
\hline Middle ( $n$ 89) & $32 \cdot 1$ & $26 \cdot 6,37 \cdot 6$ & $36 \cdot 3$ & $9 \cdot 3$ & & $0 \cdot 6^{\mathrm{a}, \mathrm{b}}$ & 0.1 & & $27 \cdot 0^{a, b}$ & $17 \cdot 8,36 \cdot 2$ & \\
\hline High (n 82) & $29 \cdot 6$ & $24 \cdot 3,34.9$ & $35 \cdot 8$ & 9.1 & 0.937 & $1 \cdot 0^{\mathrm{c}}$ & 0.1 & 0.006 & $54.9^{c}$ & $44 \cdot 1,65 \cdot 7$ & $<0.001$ \\
\hline
\end{tabular}

hs-CRP, high-sensitivity C-reactive protein.

a,b,c Values within a column with unlike superscript letters were significantly different $(P<0.05$; Student's $t$ test, Wilcoxon rank test or Kruskal-Wallis test).

* Significant difference as determined by the Student's $t$ test.

† Significant difference as determined by the Wilcoxon rank test or Kruskal-Wallis test.

$\ddagger$ Significant difference as determined by the $\chi^{2}$ test. 
Table 2. High-sensitivity C-reactive protein concentration (mg/l) according to micronutrient status and cardiometabolic risk factors (Geometric mean values with their standard errors)

\begin{tabular}{|c|c|c|c|c|c|c|c|c|c|}
\hline & \multicolumn{3}{|c|}{ All $(n 277)$} & \multicolumn{3}{|c|}{ Women ( $n$ 148) } & \multicolumn{3}{|c|}{ Men $(n 129)$} \\
\hline & Geometric mean & SE & $P^{\star}$ & Geometric mean & SE & $P^{\star}$ & Geometric mean & SE & $P^{\star}$ \\
\hline \multicolumn{10}{|c|}{ Micronutrient deficiency markers } \\
\hline \multicolumn{10}{|c|}{ Anaemia } \\
\hline Yes & 0.8 & 0.2 & & 0.8 & 0.2 & & 0.9 & 0.4 & \\
\hline No & 0.7 & 0.1 & 0.266 & 0.8 & $0 \cdot 2$ & 0.988 & 0.7 & 0.2 & 0.094 \\
\hline \multicolumn{10}{|c|}{ Low ferritin (Fe depletion) } \\
\hline Yes & 0.6 & 0.3 & & 0.5 & 0.2 & & 1.3 & $1 \cdot 1$ & \\
\hline No & 0.8 & 0.1 & 0.114 & 0.9 & 0.2 & 0.008 & 0.7 & 0.2 & 0.254 \\
\hline \multicolumn{10}{|c|}{ Vitamin A deficiency } \\
\hline Yes & 1.0 & 0.4 & & 1.2 & 0.3 & & 0.8 & 0.8 & \\
\hline No & 0.7 & 0.1 & 0.064 & 0.7 & 0.2 & 0.022 & 0.7 & 0.2 & 0.777 \\
\hline \multicolumn{10}{|c|}{ Cardiometabolic risk factors } \\
\hline \multicolumn{10}{|c|}{ BMI $\left(\mathrm{kg} / \mathrm{m}^{2}\right)$} \\
\hline$<18.5$ & $0.5^{\mathrm{a}}$ & 0.3 & & 0.4 & 0.3 & & $0.5^{\mathrm{a}}$ & 0.4 & \\
\hline $18 \cdot 5-25$ & $0.6^{\mathrm{a}, \mathrm{b}}$ & 0.1 & & 0.6 & 0.2 & & $0.6^{\mathrm{a}, \mathrm{b}}$ & 0.2 & \\
\hline$\geq 25$ & $1 \cdot 6^{\mathrm{c}}$ & 0.2 & $<0.001$ & 1.4 & 0.2 & $<0.001$ & $2 \cdot 0^{\mathrm{C}}$ & 0.5 & 0.001 \\
\hline \multicolumn{10}{|c|}{ Abdominal obesity } \\
\hline Yes & 1.3 & 0.2 & & 1.2 & 0.2 & & $2 \cdot 6$ & 0.8 & \\
\hline No & 0.6 & 0.1 & $<0.001$ & 0.5 & 0.2 & $<0.001$ & 0.7 & 0.2 & 0.007 \\
\hline \multicolumn{10}{|l|}{ High body fat } \\
\hline Yes & 1.7 & 0.2 & & 1.6 & 0.2 & & $2 \cdot 4$ & 0.2 & \\
\hline \multirow{2}{*}{\multicolumn{10}{|c|}{ High blood pressure }} \\
\hline & & & & & & & & & \\
\hline Yes & 0.8 & 0.2 & & 0.8 & 0.2 & & 0.8 & 0.3 & \\
\hline No & 0.7 & 0.1 & 0.558 & 0.8 & 0.2 & 0.794 & 0.7 & 0.2 & 0.650 \\
\hline \multicolumn{10}{|l|}{ Hyperglycaemia } \\
\hline Yes & 0.7 & 0.2 & & 0.8 & 0.2 & & 0.6 & 0.2 & \\
\hline No & 0.8 & 0.1 & 0.402 & 0.8 & 0.2 & 0.974 & 0.8 & 0.2 & 0.265 \\
\hline \multicolumn{10}{|l|}{ High LDL-C } \\
\hline Yes & 1.4 & 0.4 & & 1.3 & 0.4 & & 1.6 & 0.9 & \\
\hline No & 0.7 & 0.1 & 0.001 & 0.7 & $0 \cdot 1$ & 0.016 & 0.7 & 0.2 & 0.046 \\
\hline \multicolumn{10}{|l|}{ Low HDL-C } \\
\hline Yes & 0.9 & 0.2 & & 0.8 & 0.3 & & 1.0 & 0.4 & \\
\hline No & 0.7 & 0.1 & 0.036 & 0.7 & 0.1 & 0.418 & 0.6 & 0.2 & 0.024 \\
\hline \multicolumn{10}{|c|}{ High TC:HDL-C ratio } \\
\hline Yes & 1.5 & 0.4 & & 1.3 & 0.3 & & $2 \cdot 0$ & 1.0 & \\
\hline No & 0.7 & 0.1 & 0.001 & 0.7 & 0.1 & 0.034 & 0.7 & 0.2 & 0.014 \\
\hline \multicolumn{10}{|c|}{ Hypertriacylglycerolaemia } \\
\hline Yes & 1.8 & 1.4 & & 2.9 & $2 \cdot 1$ & & 0.9 & 0.4 & \\
\hline No & 0.7 & 0.1 & 0.056 & 0.7 & 0.1 & 0.049 & 0.7 & 0.2 & 0.502 \\
\hline \multicolumn{10}{|c|}{ Insulin resistance } \\
\hline Yes & 0.8 & 0.1 & & 0.7 & 0.2 & & 0.8 & 0.2 & \\
\hline No & 0.7 & 0.2 & 0.463 & 0.8 & 0.2 & 0.618 & 0.5 & 0.3 & 0.059 \\
\hline \multicolumn{10}{|c|}{ Clustering of MetS factors } \\
\hline Zero factors & 0.7 & 0.3 & & 0.7 & 0.3 & & 0.7 & 0.4 & \\
\hline One factor & 0.6 & 0.1 & & 0.6 & 0.2 & & 0.6 & 0.1 & \\
\hline Two factors & 1.0 & 0.2 & & 1.0 & 0.3 & & 1.0 & 0.4 & \\
\hline MetS & $1 \cdot 1$ & 0.4 & 0.004 & $1 \cdot 1$ & 0.3 & 0.043 & $1 \cdot 1$ & 0.9 & 0.058 \\
\hline
\end{tabular}

LDL-C, LDL-cholesterol; HDL-C, HDL-cholesterol; TC, total cholesterol; MetS, metabolic syndrome.

$a, b, c$ Mean values within a column with unlike superscript letters were significantly different $(P<0.05$; Wilcoxon rank test or Kruskal-Wallis test).

* Significant difference as determined by the Wilcoxon rank test or Kruskal-Wallis test.

independently associated with low-grade inflammation (Table 5). Partial correlation between deficiency markers and log (hs-CRP) controlling for income, sex, age and education level was positive and significant for ferritin $(r 0 \cdot 194 ; P=0 \cdot 002)$, but this correlation disappeared when including BMI, WC, body fat and TAG concentrations as control variables (data not shown).

\section{Discussion}

To the best of our knowledge, the present study represents one of the first to be performed on inflammation and CMRF in sub-Saharan Africa. The present results showed a consistent and significant association between overweight/obesity, abdominal obesity and percentage body fat and elevated hs-CRP after adjusting for sociodemographic factors and blood level of $\mathrm{Hb}$, and serum ferritin and retinol. These data are in accordance with those of Kao et al. ${ }^{(39)}$ who reported, after controlling for several parameters including demographics, health behaviours, serum folate and vitamin $\mathrm{B}_{12}$, a similar association between hs-CRP, BMI and central adiposity. A better characterisation of this association in the regression models showed that abdominal adiposity and TAG 
Table 3. Risk of elevated high-sensitivity C-reactive protein (hs-CRP) level as related to micronutrient deficiency and cardiometabolic risk markers

(Odds ratios and $95 \%$ confidence intervals)

\begin{tabular}{|c|c|c|c|c|c|}
\hline & $n$ & $\% \mathrm{hs}-\mathrm{CRP}>1 \mathrm{mg} / \mathrm{l}$ & OR & $95 \% \mathrm{Cl}$ & $P^{\star}$ \\
\hline \multicolumn{6}{|c|}{ Micronutrient deficiency markers } \\
\hline \multicolumn{6}{|c|}{ Anaemia } \\
\hline No & 205 & $37 \cdot 6$ & 1 & & \\
\hline Yes & 72 & 44.4 & 1.6 & $0.9,2.8$ & 0.079 \\
\hline \multicolumn{6}{|c|}{ Low ferritin (Fe depletion) } \\
\hline No & 233 & $40 \cdot 8$ & 1 & & \\
\hline Yes & 44 & $31 \cdot 8$ & 0.8 & $0.4,1.5$ & 0.462 \\
\hline \multicolumn{6}{|c|}{ Vitamin A deficiency } \\
\hline No & 239 & $36 \cdot 4$ & 1 & & \\
\hline Yes & 37 & $59 \cdot 5$ & 2.5 & $1 \cdot 2,5 \cdot 2$ & 0.015 \\
\hline \multicolumn{6}{|c|}{ Cardiometabolic risk factors } \\
\hline \multicolumn{6}{|c|}{ BMI $\left(\mathrm{kg} / \mathrm{m}^{2}\right)$} \\
\hline $18 \cdot 5-25$ & 178 & $27 \cdot 5$ & 1 & & \\
\hline$<18.5$ & 29 & $31 \cdot 0$ & $1 \cdot 3$ & $0.5,3 \cdot 1$ & 0.613 \\
\hline$\geq 25$ & 70 & 72.9 & $6 \cdot 9$ & $3 \cdot 6,13 \cdot 3$ & $<0.001$ \\
\hline \multicolumn{6}{|c|}{ Abdominal obesity } \\
\hline No & 208 & $30 \cdot 8$ & 1 & & \\
\hline Yes & 69 & $63 \cdot 8$ & $4 \cdot 0$ & $2 \cdot 2,7 \cdot 3$ & $<0.001$ \\
\hline \multicolumn{6}{|l|}{ High body fat } \\
\hline No & 209 & $26 \cdot 8$ & 1 & & \\
\hline Yes & 68 & $79 \cdot 1$ & $10 \cdot 2$ & $5 \cdot 1,20 \cdot 3$ & $<0.001$ \\
\hline \multicolumn{6}{|c|}{ High blood pressure } \\
\hline No & 183 & $37 \cdot 2$ & 1 & & \\
\hline Yes & 94 & $43 \cdot 6$ & $1 \cdot 2$ & $0 \cdot 7,2 \cdot 1$ & 0.442 \\
\hline \multicolumn{6}{|l|}{ Hyperglycaemia } \\
\hline No & 172 & $42 \cdot 4$ & 1 & & \\
\hline Yes & 105 & $36 \cdot 3$ & 0.7 & $0.4,1 \cdot 2$ & 0.178 \\
\hline \multicolumn{6}{|l|}{ High LDL-C } \\
\hline No & 249 & $36 \cdot 5$ & 1 & & \\
\hline Yes & 28 & $64 \cdot 3$ & 3.4 & $1 \cdot 5,7 \cdot 8$ & 0.004 \\
\hline \multicolumn{6}{|l|}{ Low HDL-C } \\
\hline No & 190 & $35 \cdot 3$ & 1 & & \\
\hline Yes & 87 & $48 \cdot 3$ & 1.6 & $1 \cdot 02,2 \cdot 8$ & 0.040 \\
\hline \multicolumn{6}{|c|}{ High TC:HDL-C ratio } \\
\hline No & 255 & $37 \cdot 3$ & 1 & & \\
\hline Yes & 22 & $63 \cdot 6$ & $3 \cdot 3$ & $1 \cdot 3,8 \cdot 3$ & 0.010 \\
\hline \multicolumn{6}{|c|}{ Hypertriacylglycerolaemia } \\
\hline No & 271 & 38.4 & 1 & & \\
\hline Yes & 6 & $83 \cdot 3$ & $7 \cdot 7$ & $0.8,69 \cdot 7$ & 0.070 \\
\hline \multicolumn{6}{|c|}{ Insulin resistance } \\
\hline No & 212 & 38.6 & 1 & & \\
\hline \multirow{2}{*}{\multicolumn{6}{|c|}{ Clustering of MetS factors }} \\
\hline & & & & & \\
\hline Zero factors & 66 & $33 \cdot 3$ & 1 & & \\
\hline One factor & 106 & $32 \cdot 1$ & 0.9 & $0.5,1.8$ & 0.864 \\
\hline Two factors & 72 & $48 \cdot 6$ & 1.9 & $0.9,3.8$ & 0.070 \\
\hline MetS & 33 & 54.5 & $2 \cdot 4$ & $1 \cdot 1,5 \cdot 6$ & 0.045 \\
\hline
\end{tabular}

LDL-C, LDL-cholesterol; HDL-C, HDL-cholesterol; TC, total cholesterol; MetS, metabolic syndrome.

${ }^{*}$ Significant difference as determined by the $\chi^{2}$ test.

were independent factors associated with hs-CRP. These results are also consistent with previous reports portraying central adiposity to be the most important determinant of low-grade chronic inflammation ${ }^{(40-42)}$, and a major source of pro-inflammatory cytokines such as IL-6, a well-identified primary CRP-stimulating factor ${ }^{(43-46)}$. This is strongly supported by a recent study reporting that in subjects matched for BMI, abdominal adiposity was associated with inflammation even in non-obese individuals ${ }^{(47)}$.

Consistent with previous studies ${ }^{(11,12,48,49)}$, we also reported a positive and significant correlation between TAG or TC:HDL-C ratio and hs-CRP even after controlling for sex, age, socio-economic and education levels, and serum $\mathrm{Hb}$, ferritin and retinol. TAG remained one of the two independent factors positively and significantly associated with hs-CRP in the regression models. Rocha et $a l^{(50)}$ recently reported that increased serum levels of NEFA and NEFA breakdown products trigger inflammatory cascades, which in turn result in elevated cytokine secretion, promoting an inflammatory milieu, which could explain our findings.

Interestingly, and in accordance with previous studies ${ }^{(12,49)}$, we found no correlation between serum LDL-C and hs-CRP. In the Women's Health Study (WHS) ${ }^{(12,49)}$, Ridker et al. ${ }^{(51)}$ demonstrated that both LDL-C and hs-CRP were independent predictors of cardiovascular events, with hs-CRP being the strongest. Indeed, $77 \%$ of the first cardiovascular events 
Table 4. Partial correlation between log (high-sensitivity C-reactive protein) and cardiometabolic risk markers after controlling for income and education level, sex, age, and micronutrient markers*

\begin{tabular}{lcr}
\hline Cardiometabolic risk markers & Correlation coefficient & \multicolumn{1}{c}{$P$} \\
\hline BMI $\left(\mathrm{kg} / \mathrm{m}^{2}\right)$ & 0.340 & $<0.001$ \\
WC $(\mathrm{cm})$ & 0.366 & $<0.001$ \\
BF $(\mathrm{kg})$ & 0.185 & 0.003 \\
SBP $(\mathrm{mmHg})$ & 0.057 & 0.362 \\
DBP $(\mathrm{mmHg})$ & 0.050 & 0.425 \\
Glycaemia $(\mathrm{mmol} / \mathrm{l})$ & 0.008 & 0.898 \\
LDL-C $(\mathrm{mmol} / \mathrm{l})$ & 0.030 & 0.628 \\
HDL-C $(\mathrm{mmol} / \mathrm{l})$ & -0.113 & 0.069 \\
TC:HDL-C ratio & 0.152 & 0.014 \\
TAG $(\mathrm{mmol} / \mathrm{l})$ & 0.274 & $<0.001$ \\
HOMA & 0.007 & 0.910 \\
\hline
\end{tabular}

WC, waist circumference; BF, body fat; SBP, systolic blood pressure; DBP diastolic blood pressure; LDL-C, LDL-cholesterol; HDL-C, HDL-cholesterol; TC, total cholesterol; HOMA, homeostasis model assessment.

${ }^{*}$ Control variables: income level, education level, age, sex, $\mathrm{Hb}$, serum ferritin and serum retinol level.

among the 27939 women included in the study occurred in those with low LDL-C, with women in the high CRP-low LDL-C' subgroup being at higher absolute risk than those in 'low CRP-high LDL-C' subgroup. In a more recent longitudinal study carried out in 27548 subjects, Pichon et al. ${ }^{(52)}$ also demonstrated that hs-CRP strongly predicted myocardial infarction (MI) and stroke, while LDL-C only predicted MI, in agreement with a reanalysis of the WHS report ${ }^{53}$. Going beyond the relative risk, these authors demonstrated that using hs-CRP rather than LDL-C as an additional criterion along with smoking, diabetes and hypertension for the estimation of the population attributable fraction $(\mathrm{PAF})^{(54)}$, elevated hs-CRP but not LDL-C increased the PAF of both MI and stroke ${ }^{(52)}$. The ability of hs-CRP to better predict cardiovascular events than LDL-C and other CMRF should be of particular concern for prevention strategies in sub-Saharan populations, taking into account the low propensity of African individuals to develop dyslipidaemia ${ }^{(55)}$. The scarcity of data on sub-Saharan populations is another issue for concern and calls for more research on the links of blood lipids with hs-CRP in this context.

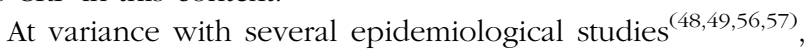
we did not find any correlation between insulin resistance and hs-CRP. Xu et al. ${ }^{(58)}$ recently reported a direct involvement of CRP in insulin resistance through inhibition of insulin signalling in endothelial cells. Several other studies have speculated on an important role for the pro-inflammatory cytokines of adipose tissue as a plausible molecular pathway linking inflammation and insulin resistance ${ }^{(59-63)}$. This may help to better explain the present results, namely the consistent association of adiposity with inflammation and the lack of association between insulin resistance and hs-CRP. Indeed, insulin resistance was not correlated with adiposity in the present study. Only $32 \%$ of insulin-resistant subjects were overweight/obese or abdominally obese (data not shown). Another possible explanation for our diverging results has to do with the detection of insulin resistance, since insulin determination is not standardised, and since HOMA-IR was used in the present study while a more direct method of assessing insulin resistance was used in the above studies.

The present study also confirms that hs-CRP is significantly elevated in individuals with multiple CMRF, as also demonstrated by the higher odds of elevated hs-CRP among subjects with the metabolic syndrome, in agreement with previous studies $^{(48,49)}$. Thus, traditional CMRF may contribute to the inflammatory process. However, more population-specific studies are still needed for a better understanding of the array of factors that may contribute to the escalating rate of cardiometabolic disease in the developing world ${ }^{(19,64)}$, especially in sub-Saharan Africa.

The present study is also one of the first to assess the relationship between hs-CRP and micronutrient deficiencies in sub-Saharan adults. We observed that vitamin A-deficient subjects were at higher odds of high hs-CRP, although serum retinol and $\log$ (hs-CRP) were not significantly correlated. A recent study in Australia reported that plasma retinol was inversely associated with 5-year cardiovascular mortality in older adults and that it was negatively and significantly correlated with $\mathrm{CRP}^{(65)}$. We could not reproduce such results, but we did find in subjects with low serum retinol a consistent trend for a higher prevalence of overweight/obesity (27.5 $v$. $23.7 \%)$, abdominal obesity (30.0 v. 22.6\%), high blood pressure ( $40.0 v .35 \cdot 6 \%)$, low HDL-C (40.0 v. 28.5\%) and insulin resistance $(27.5 v \cdot 24.8 \%)$ (data not shown). It is now established that active acute-phase response of inflammation (CRP $\geq 10 \mathrm{mg} / \mathrm{l}$ ) is associated with depressed serum retinol, due to increased urinary loss of retinol ${ }^{(66)}$ while synthesis of retinol-binding protein is reduced ${ }^{(67)}$, but this has not been demonstrated for low-grade inflammation.

We also found a positive correlation between serum ferritin levels and $\log$ (hs-CRP), which is consistent with previous reports ${ }^{(68,69)}$ even if this correlation was no longer significant after controlling for adiposity factors. There is increasing evidence of a link between low-grade inflammation and $\mathrm{Fe}$ deficiency, mainly in overweight/obese subjects, who are known to be at increased risk of Fe deficiency ${ }^{(70,71)}$. A likely explanation is that chronic adiposity-related inflammation increases circulating hepcidin, thereby decreasing intestinal Fe

Table 5. Multiple linear regression models of cardiometabolic and nutrition deficiency markers on log (high-sensitivity C-reactive protein) (hs-CRP)

\begin{tabular}{|c|c|c|c|c|}
\hline \multirow[b]{3}{*}{ Independent variables } & \multicolumn{4}{|c|}{ Dependent variable: log (hs-CRP) } \\
\hline & \multicolumn{2}{|c|}{ Model 1} & \multicolumn{2}{|c|}{ Model 2} \\
\hline & $\beta$ & $P$ & $\beta$ & $P$ \\
\hline BMI $\left(\mathrm{kg} / \mathrm{m}^{2}\right)$ & 0.037 & 0.788 & 0.036 & 0.799 \\
\hline WC (cm) & 0.307 & 0.015 & 0.306 & 0.018 \\
\hline $\mathrm{BF}(\mathrm{kg})$ & 0.010 & 0.896 & 0.009 & 0.904 \\
\hline HDL-C (mmol/l) & -0.067 & 0.312 & -0.066 & 0.328 \\
\hline TC:HDL-C ratio & 0.032 & 0.689 & 0.032 & 0.693 \\
\hline TAG (mmol/l) & 0.156 & 0.028 & 0.158 & 0.027 \\
\hline $\mathrm{Hb}(\mathrm{g} / \mathrm{l})$ & - & - & -0.002 & 0.970 \\
\hline Ferritin $(\mu \mathrm{g} / \mathrm{l})$ & - & - & 0.093 & 0.155 \\
\hline Serum retinol $(\mu \mathrm{mol} / \mathrm{l})$ & - & - & -0.011 & 0.863 \\
\hline
\end{tabular}

WC, waist circumference; BF, body fat; HDL-C, HDL-cholesterol; TC, total cholesterol. 
absorption or increasing reticuloendothelial Fe sequestration ${ }^{(72-74)}$. A recent study from South Africa reported a positive association between BMI, WC and ferritin, while at the same time serum Fe concentration decreased with increasing BMI ${ }^{(75)}$.

There are several limitations to the present study. The crosssectional design does not allow any inference on causal relationships between variables. It did not permit confirmation of the role of hs-CRP as an independent predictor of cardiovascular events, which could only be done in a prospective study. Furthermore, the study is only representative of one district in Ouagadougou and the results can only be extrapolated to the whole urban population of Burkina Faso with caution. Despite these limitations, the study provides useful data on the relationship between CMRF, micronutrient deficiencies and hs-CRP in adults.

In the compelling need for effective preventive strategies against the unprecedented explosion of CMRF in sub-Saharan Africa, it is important to unravel the network of multiple risk factors which could interact with one another in different ways from what is observed in developed countries. Despite the fact that hs-CRP is a sensitive marker, and that it could be influenced by several endemic disease conditions in subSaharan Africa, the present study showed its consistent relationship with some traditional CMRF, suggesting that hs-CRP could be associated with the ongoing rise in cardiometabolic diseases. It has been hypothesised that hs-CRP is an independent predictor of cardiovascular events. Given the high rate of mortality attributable to cardiometabolic diseases in sub-Saharan Africa, confirmation of this in such a population would provide decision makers with a useful tool for prevention strategies. It appears important, therefore, to conduct more studies on hs-CRP to better understand its implications with CMRF.

\section{Acknowledgements}

The present study received funding from the Canadian International Development Agency. We gratefully acknowledge the technical and field support provided by the Institut de Recherche en Sciences de la Santé (IRSS) and the Institut Supérieur des Sciences de la Population (ISSP). We thank Professor Somé Issa of Université de Ouagadougou and Professor Jean-Louis Guéant of Université de Nancy for laboratory analyses. We also thank the participants of the 'Population Observatory of Ouagadougou' and all field workers involved in the study. A. N. Z. developed the study protocol as his $\mathrm{PhD}$ project; he collected and analysed the data and drafted the manuscript. G. R. was involved in the study design and paper revision. H. F. D. designed the study, and supervised data analysis and paper revision. C. R. provided the sampling database, assisted with statistics and revised the manuscript. The authors have no conflicts of interest.

\section{References}

1. Cesari M, Penninx BW, Newman AB, et al. (2003) Inflammatory markers and onset of cardiovascular events: results from the Health ABC study. Circulation 108, 2317-2322.
2. Han TS, Sattar N, Williams K, et al. (2002) Prospective study of $\mathrm{C}$-reactive protein in relation to the development of diabetes and metabolic syndrome in the Mexico City Diabetes Study. Diabetes Care 25, 2016-2021.

3. Ridker PM, Cushman M, Stampfer MJ, et al. (1997) Inflammation, aspirin, and the risk of cardiovascular disease in apparently healthy men. $N$ Engl J Med 336, 973-979.

4. Ridker PM, Hennekens CH, Buring JE, et al. (2000) C-reactive protein and other markers of inflammation in the prediction of cardiovascular disease in women. $N$ Engl J Med 342, 836-843.

5. Danesh J, Whincup P, Walker M, et al. (2000) Low grade inflammation and coronary heart disease: prospective study and updated meta-analyses. BMJ 321, 199-204.

6. Pai JK, Pischon T, Ma J, et al. (2004) Inflammatory markers and the risk of coronary heart disease in men and women. $N$ Engl J Med 351, 2599-2610.

7. Benzaquen LR, Yu H \& Rifai N (2002) High sensitivity C-reactive protein: an emerging role in cardiovascular risk assessment. Crit Rev Clin Lab Sci 39, 459-497.

8. Ridker PM (2009) Testing the inflammatory hypothesis of atherothrombosis: scientific rationale for the cardiovascular inflammation reduction trial (CIRT). J Thromb Haemost $\mathbf{7}$, Suppl. 1, 332-339.

9. Kaptoge S, Di Angelantonio E, Lowe G, et al. (2010) $\mathrm{C}$-reactive protein concentration and risk of coronary heart disease, stroke, and mortality: an individual participant meta-analysis. Lancet 375, 132-140.

10. Danesh J, Wheeler JG, Hirschfield GM, et al. (2004) $\mathrm{C}$-reactive protein and other circulating markers of inflammation in the prediction of coronary heart disease. $N$ Engl J Med 350, 1387-1397.

11. Miller M, Zhan M \& Havas S (2005) High attributable risk of elevated C-reactive protein level to conventional coronary heart disease risk factors: the Third National Health and Nutrition Examination Survey. Arch Intern Med $\mathbf{1 6 5}$, 2063-2068.

12. Saito M, Ishimitsu T, Minami J, et al. (2003) Relations of plasma high-sensitivity $\mathrm{C}$-reactive protein to traditional cardiovascular risk factors. Atherosclerosis 167, 73-79.

13. Hurt N, Smith T, Teuscher T, et al. (1994) Do high levels of C-reactive protein in Tanzanian children indicate malaria morbidity? Clin Diagn Lab Immunol 1, 437-444.

14. Imrie H, Fowkes FJ, Michon P, et al. (2007) Low prevalence of an acute phase response in asymptomatic children from a malaria-endemic area of Papua New Guinea. Am J Trop Med Hyg 76, 280-284

15. Abraham K, Muller C, Gruters A, et al. (2003) Minimal inflammation, acute phase response and avoidance of misclassification of vitamin A and iron status in infants importance of a high-sensitivity C-reactive protein (CRP) assay. Int J Vitam Nutr Res 73, 423-430.

16. Schweigert FJ (2001) Inflammation-induced changes in the nutritional biomarkers serum retinol and carotenoids. Curr Opin Clin Nutr Metab Care 4, 477-481.

17. Stephensen CB \& Gildengorin G (2000) Serum retinol, the acute phase response, and the apparent misclassification of vitamin A status in the third National Health and Nutrition Examination Survey. Am J Clin Nutr 72, 1170-1178.

18. World Health Organization (2003) Diet, Nutrition and the Prevention of Chronic Diseases. Joint WHO/FAO Expert Consultation. WHO Technical Report Series no. 916. Geneva: WHO.

19. Abegunde DO, Mathers CD, Adam T, et al. (2007) The burden and costs of chronic diseases in low-income and middle-income countries. Lancet 370, 1929-1938. 
20. Misra A \& Khurana L (2008) Obesity and the metabolic syndrome in developing countries. J Clin Endocrinol Metab 93, S9-S30.

21. Abubakari AR, Lauder W, Agyemang C, et al. (2008) Prevalence and time trends in obesity among adult West African populations: a meta-analysis. Obes Rev 9, 297-311.

22. Abubakari AR, Lauder W, Jones MC, et al. (2009) Prevalence and time trends in diabetes and physical inactivity among adult West African populations: the epidemic has arrived. Public Health 123, 602-614.

23. Zeba AN, Delisle HF, Renier G, et al. (2012) The double burden of malnutrition and cardiometabolic risk widens the gender and socio-economic health gap: a study among adults in Burkina Faso (West Africa). Public Health Nutr (epublication ahead of print version 30 March 2012)

24. City Development Strategy (2007) Etude diagnostique de l'agglomération de Ouagadougou. Ouagadougou: CDS.

25. Niakara A, Fournet F, Gary J, et al. (2007) Hypertension, urbanization, social and spatial disparities: a cross-sectional population-based survey in a West African urban environment (Ouagadougou, Burkina Faso). Trans R Soc Trop Med Hyg 101, 1136-1142.

26. Direction de la Nutrition (2006) Analyse complémentaire de la situation nutritionnelle au Burkina Faso: Rapport final. Ouagadougou: Ministère de la Santé du Burkina Faso.

27. Lohman T, Roche A \& Martorell R (1988) Anthropometric Standardization Reference Manual. Champaign, IL: Human Kinetics Books.

28. World Health Organization (2000) Obesity: Preventing and Managing the Global Epidemic. Report of a WHO Consultation on Obesity. WHO Technical Report Series no. 894. Geneva: WHO.

29. Alberti KG, Eckel RH, Grundy SM, et al. (2009) Harmonizing the metabolic syndrome: a joint interim statement of the International Diabetes Federation Task Force on Epidemiology and Prevention; National Heart, Lung, and Blood Institute; American Heart Association; World Heart Federation; International Atherosclerosis Society; and International Association for the Study of Obesity. Circulation 120, 1640-1645.

30. Sun SS, Chumlea WC, Heymsfield SB, et al. (2003) Development of bioelectrical impedance analysis prediction equations for body composition with the use of a multicomponent model for use in epidemiologic surveys. Am J Clin Nutr 77, 331-340.

31. Jackson AS, Stanforth PR, Gagnon J, et al. (2002) The effect of sex, age and race on estimating percentage body fat from body mass index: The Heritage Family Study. Int J Obes Relat Metab Disord 26, 789-796.

32. Pearson TA, Mensah GA, Alexander RW, et al. (2003) Markers of inflammation and cardiovascular disease: application to clinical and public health practice: a statement for healthcare professionals from the Centers for Disease Control and Prevention and the American Heart Association. Circulation 107, 499-511.

33. Ridker PM, Wilson PW \& Grundy SM (2004) Should C-reactive protein be added to metabolic syndrome and to assessment of global cardiovascular risk? Circulation 109, 2818-2825.

34. World Health Organization (1999) The Metabolic Syndrome. Definition, Diagnosis and Classification of Diabetes Mellitus and its Complications. Part 1: Diagnosis and Classification of Diabetes Mellitus. Geneva: WHO.

35. Millan J, Pinto X, Munoz A, et al. (2009) Lipoprotein ratios: physiological significance and clinical usefulness in cardiovascular prevention. Vasc Health Risk Manag 5, 757-765.
36. Matthews DR, Hosker JP, Rudenski AS, et al. (1985) Homeostasis model assessment: insulin resistance and $\beta$-cell function from fasting plasma glucose and insulin concentrations in man. Diabetologia 28, 412-419.

37. World Health Organization (2009) Global Prevalence of Vitamin A Deficiency in Populations at Risk 1995-2005. WHO Global Database on Vitamin A Deficiency. Geneva: WHO.

38. World Health Organization (2004) Assessing the Iron Status of Populations: Including Literature Reviews: Report of a Joint WHO/CDC and Prevention Technical Consultation on the Assessment of Iron Status at the Population Level, 6-8 April 2004. Geneva: WHO.

39. Kao TW, Lu IS, Liao KC, et al. (2009) Associations between body mass index and serum levels of C-reactive protein. $S$ Afr Med J 99, 326-330.

40. Santos AC, Lopes C, Guimaraes JT, et al. (2005) Central obesity as a major determinant of increased high-sensitivity C-reactive protein in metabolic syndrome. Int $J$ Obes (Lond) 29, 1452-1456.

41. Hwang JJ, Li HY, Shieh GJ, et al. (2008) Illustrating the roles of C-reactive protein in the development of the metabolic syndrome in women - a cross-racial validation. Nutr Metab Cardiovasc Dis 18, 671-677.

42. Nakamura H, Ito H, Egami Y, et al. (2008) Waist circumference is the main determinant of elevated C-reactive protein in metabolic syndrome. Diabetes Res Clin Pract 79, 330-336.

43. Brooks GC, Blaha MJ \& Blumenthal RS (2010) Relation of C-reactive protein to abdominal adiposity. Am J Cardiol 106, 56-61.

44. McDade TW, Rutherford JN, Adair L, et al. (2008) Adiposity and pathogen exposure predict C-reactive protein in Filipino women. J Nutr 138, 2442-2447.

45. Park HS, Park JY \& Yu R (2005) Relationship of obesity and visceral adiposity with serum concentrations of CRP, TNF- $\alpha$ and IL-6. Diabetes Res Clin Pract 69, 29-35.

46. Visser M, Bouter LM, McQuillan GM, et al. (1999) Elevated C-reactive protein levels in overweight and obese adults. JAMA 282, 2131-2135.

47. Lapice E, Maione S, Patti L, et al. (2009) Abdominal adiposity is associated with elevated C-reactive protein independent of BMI in healthy nonobese people. Diabetes Care 32, $1734-1736$.

48. Jeemon P, Prabhakaran D, Ramakrishnan L, et al. (2011) Association of high sensitive C-reactive protein (hsCRP) with established cardiovascular risk factors in the Indian population. Nutr Metab (Lond) $\mathbf{8}, 19$

49. Olsen MH, Christensen MK, Hansen TW, et al. (2006) High-sensitivity C-reactive protein is only weakly related to cardiovascular damage after adjustment for traditional cardiovascular risk factors. J Hypertens 24, 655-661.

50. Rocha VZ \& Libby P (2009) Obesity, inflammation, and atherosclerosis. Nat Rev Cardiol 6, 399-409.

51. Ridker PM, Rifai N, Rose L, et al. (2002) Comparison of C-reactive protein and low-density lipoprotein cholesterol levels in the prediction of first cardiovascular events. $N$ Engl J Med 347, 1557-1565.

52. Pischon T, Mohlig M, Hoffmann K, et al. (2007) Comparison of relative and attributable risk of myocardial infarction and stroke according to C-reactive protein and low-density lipoprotein cholesterol levels. Eur J Epidemiol 22, 429-438.

53. Everett BM, Kurth T, Buring JE, et al. (2006) The relative strength of C-reactive protein and lipid levels as determinants of ischemic stroke compared with coronary heart disease in women. J Am Coll Cardiol 48, 2235-2242. 
54. Rockhill B, Newman B \& Weinberg C (1998) Use and misuse of population attributable fractions. Am J Public Health $\mathbf{8 8}$, 15-19.

55. Zoratti R (1998) A review on ethnic differences in plasma triglycerides and high-density-lipoprotein cholesterol: is the lipid pattern the key factor for the low coronary heart disease rate in people of African origin? Eur J Epidemiol 14, 9-21.

56. Blake GJ, Rifai N, Buring JE, et al. (2003) Blood pressure, C-reactive protein, and risk of future cardiovascular events. Circulation 108, 2993-2999.

57. McLaughlin T, Abbasi F, Lamendola C, et al. (2002) Differentiation between obesity and insulin resistance in the association with C-reactive protein. Circulation 106, 2908-2912.

58. Xu JW, Morita I, Ikeda K, et al. (2007) C-reactive protein suppresses insulin signaling in endothelial cells: role of spleen tyrosine kinase. Mol Endocrinol 21, 564-573.

59. Donath MY \& Shoelson SE (2011) Type 2 diabetes as an inflammatory disease. Nat Rev Immunol 11, 98-107.

60. Goldfine AB, Fonseca V \& Shoelson SE (2011) Therapeutic approaches to target inflammation in type 2 diabetes. Clin Chem 57, 162-167.

61. Heilbronn LK \& Campbell LV (2008) Adipose tissue macrophages, low grade inflammation and insulin resistance in human obesity. Curr Pharm Des 14, 1225-1230.

62. Oliver E, McGillicuddy F, Phillips C, et al. (2010) The role of inflammation and macrophage accumulation in the development of obesity-induced type 2 diabetes mellitus and the possible therapeutic effects of long-chain n-3 PUFA. Proc Nutr Soc 69, 232-243.

63. Shoelson SE, Lee J \& Goldfine AB (2006) Inflammation and insulin resistance. J Clin Invest 116, 1793-1801.

64. International Diabetes Federation (2009) Diabetes Atlas, 4th ed. Brussels: IDF.

65. Brazionis L, Walker KZ, Itsiopoulos C, et al. (2011) Plasma retinol: a novel marker for cardiovascular disease mortality in Australian adults. Nutr Metab Cardiovasc Dis (epublication ahead of print version 25 November 2011).

66. Stephensen CB, Alvarez JO, Kohatsu J, et al. (1994) Vitamin A is excreted in the urine during acute infection. Am J Clin Nutr 60, 388-392.
67. Rosales FJ \& Ross AC (1998) A low molar ratio of retinol binding protein to transthyretin indicates vitamin A deficiency during inflammation: studies in rats and a posterior analysis of vitamin A-supplemented children with measles. J Nutr 128, 1681-1687.

68. Sung KC, Kang JH \& Shin HS (2007) Relationship of cardiovascular risk factors and serum ferritin with C-reactive protein. Arch Med Res 38, 121-125.

69. Williams MJ, Poulton R \& Williams S (2002) Relationship of serum ferritin with cardiovascular risk factors and inflammation in young men and women. Atherosclerosis $\mathbf{1 6 5}$, 179-184.

70. Cepeda-Lopez AC, Osendarp SJ, Melse-Boonstra A, et al. (2011) Sharply higher rates of iron deficiency in obese Mexican women and children are predicted by obesityrelated inflammation rather than by differences in dietary iron intake. Am J Clin Nutr 93, 975-983.

71. Zimmermann MB, Zeder C, Muthayya S, et al. (2008) Adiposity in women and children from transition countries predicts decreased iron absorption, iron deficiency and a reduced response to iron fortification. Int $J$ Obes (Lond) 32, 1098-1104.

72. Aeberli I, Hurrell RF \& Zimmermann MB (2009) Overweight children have higher circulating hepcidin concentrations and lower iron status but have dietary iron intakes and bioavailability comparable with normal weight children. Int J Obes (Lond) 33, 1111-1117.

73. Cepeda-Lopez AC, Aeberli I \& Zimmermann MB (2010) Does obesity increase risk for iron deficiency? A review of the literature and the potential mechanisms. Int J Vitam Nutr Res 80, 263-270.

74. Tussing-Humphreys LM, Nemeth E, Fantuzzi G, et al. (2010) Elevated systemic hepcidin and iron depletion in obese premenopausal females. Obesity (Silver Spring) 18, 1449-1456.

75. Aderibigbe OR, Pisa PT, Mamabolo RL, et al. (2011) The relationship between indices of iron status and selected anthropometric cardiovascular disease risk markers in an African population: the THUSA study. Cardiovasc J Afr 22, 249-256. 